\title{
INCONGRUÊNCIA IDENTITÁRIA E DIPLOMACIA ESPECTRAL
}

\section{Julian Alexander Brzozowski ${ }^{1}$}

Aí, a força da yãkoana me pegava e em seguida me fazia morrer. Eu rolava e me debatia no chão, como um fantasma. [...] Minha pele permanecia estirada no chão, enquanto os xapiri pegavam minha imagem e levavam para longe, muito ligeiros. Eu voava com eles até as costas do céu, onde vivem os mortos, ou para o mundo subterrâneo dos ancestrais aõpatari.

Davi Kopenawa, A Queda do Céu

I am a ghost wanting what every ghost wants - a body.

William S. Burroughs, Naked Lunch

\begin{abstract}
Resumo: Pode o sujeito coincidir consigo mesmo? A negativa a essa indagação é pedra de toque da psicanálise, resposta clínica a uma transladação do pensamento ocidental preparada nos meados do século XIX, que encontrará sua concretude em efervescência a partir da entrada no século seguinte. Um grande movimento do espírito, marcado pela exaustão do obsessivo labor filosófico em torno de um absoluto, perfeito e infinito, abre o espaço para uma exploração científica das paisagens onde o cogito falha: no campo da psicanálise, Freud, o inconsciente e suas histéricas; no dos Estudos Culturais, Warburg, o Atlas Mnemosyne e sua esquizofrenia. Afetos organizados em regiões além do regime do sentido, de natureza espectral, retornam sintomaticamente demandando atenção, nos momentos em que o desejo de autocongruência psicossomática busca executar materializações técnicas por natureza intransponíveis.
\end{abstract}

Palavras-chave: Espectrologia. Sintoma. Incongruência. Daímon.

1 Doutorando em Literatura pela Universidade Federal de Santa Catarina (UFSC). Bolsista CAPES. E-mail: brzozowskijulian@gmail.com. 


\title{
1. COSMOS DIASTÁSICO
}

Uma das histórias possíveis do pensamento ocidental se desenha ao redor da necessidade de estabelecimento psíquico de um regime absoluto de Ser, cuja contemplação, como na elaboração conhecida pelo nome de demônio de Laplace, permitiria o cálculo e compreensão de toda movimentação da matéria:

\begin{abstract}
De um ponto de vista metafísico, qualquer que seja o conceito que se faça da liberdade da vontade, as suas manifestações (Erscheinungen) - as ações humanas -, como todo outro acontecimento natural, são determinadas por leis naturais universais. A história, que se ocupa da narrativa dessas manifestações, por mais profundamente ocultas que possam estar as suas causas, permite todavia esperar que, com a observação, em suas linhas gerais, do jogo da liberdade da vontade humana, ela possa descobrir aí um curso regular - dessa forma, o que se mostra confuso e irregular nos sujeitos individuais poderá ser reconhecido, no conjunto da espécie, como um desenvolvimento continuamente progressivo, embora lento, das suas disposições originais. ${ }^{2}$
\end{abstract}

A busca pelo estabelecimento de tais disposições originais (arché) como estrutura arquetípica da construção universal sincrônica, marcadamente determinista, projeta suas ambições por sobre uma corrente de pensadores assombrados pelo desejo de um Todo Único (hen) completo, perfeito e infinito e necessariamente Outro: isto é, para com o qual a incompletude, a imperfeição e a finitude humanas estariam em idiossincrático afastamento até, segundo a sugestão de traços narrativos semitas acrescidos à fábula filosófica, o derradeiro momento do episódio messiânico. Somente então a perfeita fusão entre o corpo sublunar e a ontologia celestial se daria em completude ôntica, um momento cujo sonho e antecipação constituem a própria versão dessa história da metafísica que localizamos e delineamos.

A capacidade de visualizar tal modelo cronológico dessa maneira indica sua própria exaustão principalmente ao posicionar as operações de sua culpa resultante, isto é, o labor psíquico decorrente de sua imponente insuficiência, como os verdadeiros fenômenos observáveis, enquanto o almejado horizonte de unicidade permanece às sombras do intelecto e da percepção. Dito de outro modo: o incansável almejo pelo Uno excreta como subproduto de sua teleologia nada menos que a vida como a conhecemos e experienciamos, necessariamente incompleta e imperfeita.

2 KANT (1986: 9). Grifos do autor. 
Pelo menos desde Nietzsche $e^{3}$ tal constatação acabou por orientar uma filosofia negativa que fez da desativação dos arcanos teóricos responsáveis pela manutenção do modelo ulteriormente messiânico seu ímpeto, sendo um de seus ápices manifestos a teoria desconstrucionista de Jacques Derrida. Entretanto, a desconstrução, enquanto desativação argumentativa dos elementos constituintes e de seus respectivos entrelaçamentos ao longo do percurso histórico de tal tradição metafísica, não deixa de estar marcada por um trabalho de olhos voltados na direção desta, uma encontrando os limites de sua proposição última na outra. A assunção que "não há saber sobre o Espírito que não seja uma temporalidade impura do espectro que desmonta e desmente a pureza do Espírito"4 em boa medida, como necessário capítulo de tal história. Desta constatação decorre a urgência de uma concepção macro-histórica da metafísica compreendida em todos os polos de sua exposição dialética até o momento.

O predomínio da figuração intelectual de significantes negativos como falta, corte e vazio e, principalmente, a ressonância psíquica que eles incutem na experiência comum de subjetivação, leva-nos a um cenário no qual a decorrente possibilidade de reconstrução da matéria (hyle) e do pensamento (nous) em enodamentos inauditos, cuja própria ebulição metamórfica é marca de sua necessária incompletude (afinal, só se pode migrar para onde não se é), deriva na/ da compreensão de um cosmos igualmente incompleto do seu ponto de vista ontológico: não mais como subproduto sacrílego que insiste em chafurdar na misteriosa impureza de seu não-ainda, mas como forma-de-vida em irrefreável eclosão. Uma das notáveis consequências do delineio de tal cenário consiste em conceber verdadeiros espaços vazios de ser, sendo só a iteração ontológica aquilo que possibilita a ideia de um não-Todo. Este seria o terreno por excelência da espectrologia conforme pensada por Fabián Ludueña:

O princípio da disjunção espectrológica se erige como contraponto ao edifício da metafísica ocidental construído sobre dois axiomas que constituem seus pilares: natura determinatur ad unum (necessariedade de um cosmos ordenado na unicidade de suas operações) e natura non facit saltus (a ordem cósmica se assenta numa continuidade ôntico-ontológica. A espectrologia tenta demonstrar que a descontinuidade é um princípio que afeta o real enquanto disjunto e, desse modo, a ordem

\footnotetext{
3 "Nós nos aguçamos e tornamo-nos frios e duros com a percepção que o mundo que habitamos é imoral, inumano e 'indivino' - por muito tempo nós o interpretamos falsa e mentirosamente, mas conforme o desejo e a vontade de nossa veneração, isto é, conforme uma necessidade. Pois o homem é um animal venerador! Mas também um animal desconfiado: e o fato de o mundo não valer o que acreditávamos é aproximadamente a coisa mais segura de que a nossa desconfiança enfim se apoderou. Quanto mais desconfiança, mais filosofia" (NIETZSCHE, 2012: 212-3).
}

4 LUDUEÑA ROMANDINI, 2018: 150. 
do Um/Múltiplo se vê acometida permanentemente pelo infra-ser do espectro que impede qualquer comunhão ontológica em um Mundo. ${ }^{5}$

Ou seja, apesar de se constituir como vizinho ao Real lacaniano, que nunca cessa de se transformar em realidade através da perfuração simbólica, o terreno do espectral diz especificamente desse vazio resoluto que, por sua vez, subjaz toda manifestação em sua incapacidade de coincidir consigo mesma. Não é o motor, a paixão criadora por excelência, mas antes a fratura que estimula o acossamento derivado da impossibilidade de conclusão do páthos dentro de suas bordas. É estranho (Unheimliche) e de-lirante, transborda os sulcos cavados para sua habitação e, sendo experiência comum a toda forma-de-vida, culmina na impossibilidade de instauração de qualquer óikos real: "a subjetivação é o produto de uma somatória de externalidades que convergem nos fantasmas que ocupam o lugar do que costumamos chamar de indivíduo"6.

Assim sendo, o espaçamento de qualquer vida compreende não somente a extensão de sua produção ${ }^{7}$ - independente se estejamos falando, através desse significante, sobre o alcance de ação das vísceras de complexos industriais; sobre os fluxos afetados pelo curso de um rio ao passar pela represa de um castor; ou sobre a porosidade de determinado pedaço de terra devido aos dutos de um formigueiro -, mas, acima de tudo, as maneiras segundo as quais esse escoamento de incongruência ontológica se manifesta nos corpos do agrupamento e gera negociações psicomateriais que procuram resolver um afeto primordial: seu estranhamento. Um estranhamento de corpo, pois " $[\mathrm{u}] \mathrm{m}$ espectro não provém nem de dentro nem de fora. Experimenta-se no corpo, mas borra seus limites e, ao mesmo tempo, configura-o em seu efetuar-se" ${ }^{\text {", }}$

[...] não porque o corpo seja o suporte material ou correlato empírico do espírito, mas porque o próprio espírito consiste em certa constituição corporal cujo arranjo sempre instável, disjuntivo, encarna uma estrutura de pensamento intensamente transformacional e, no limite, assubjetiva. Espírito é corpo, e corpo é espectro. ${ }^{9}$

5 Ibid., 192-3.

6 Ibid., 86.

7 Entendemos produção sob o amplíssimo escopo de compreensão do qual faz uso Marx, como "alteração da forma das matérias": "Ao produzir, o homem pode apenas proceder como a própria natureza, isto é, pode apenas alterar a forma das matérias" (MARX, 2013: 120).

8 LUDUEÑA ROMANDINI, 2018: 195.

9 VALENTIM, Marco Antonio, 2018: 234 
Um corpo disjunto, portanto espectral, do qual sua qualidade fraturada não enrubesce frente ao mundo: "[a] espectrologia [...] pressupõe o postulado de um cosmos diastásico"10, no qual o ser humano figura como epifenômeno tão assimétrico quanto seu entorno. De fato, é somente uma disjuntologia que permite pensar os momentos em que "anthropos descansa do pensar", momentos de "importância decisiva"11 como o sonho, o chiste ou a loucura: episódios nos quais Outras vozes se fazem manifestas e desafiam a necessidade de congruência do cogito. A leitura decorrente denota, portanto, a convicção de que "todo regime de governo é também uma política do sonho"12.

\title{
2. BIOPOLÍTICA E RECALQUE ESPECTRAL
}

A ideia antropocêntrica da idiossincrática disposição de Homo para vislumbrar a clareira (Lichtung) heideggeriana deve necessariamente partir de uma visão da Natureza como um complexo maquínico obstinadamente determinado em sua práxis, da qual este não desvia sequer por um segundo. A concepção exposta por Alexander von Humboldt nas primeiras páginas da introdução de seu Cosmos, intimamente atrelada ao princípio imperialista, não será algo distante de nosso imaginário comum:

\begin{abstract}
Aquele que consegue traçar, através dos tempos idos, o curso de nosso conhecimento até sua fonte primitiva, aprenderá da história como, por milhares de anos, o homem tem trabalhado, em meio às sempre recorrentes mudanças da forma, para reconhecer a invariabilidade das leis naturais, e tem através da força da mente gradativamente subjugado uma grande porção do mundo físico ao seu domínio. ${ }^{13}$
\end{abstract}

Esse desencontro entre a invariabilidade das leis naturais, a variabilidade das formas e o desenvolvimento gradativo da psique humana na apreensão de tal imutabilidade a seu favor constitui um magnânimo capítulo da história da civilização. A ideia geral de uma domesticação do mundo, isto é, a subsunção de kosmos em óikos ou a introjeção procrustiana de physis em nómos, virá a inspirar, no campo das ciências sociais, um léxico titubeante cuja mescla de terminologias advindas da biologia comparada e da medicina culminará na concepção de um Estado como forma de vida. O termo, título do livro de 1916 do sueco Rudolf

10 LUDUEÑA ROMANDINI, 2018: 185.

11 Ibid.:116.

12 Ibid.: 21.

13 HUMBOLDT, 1864: 1-2. 
Kjellén (Staten son livsform), antecede o primeiro registro do conceito de biopolítica pelas mãos de seu mesmo autor nas Grundriß Zu Einem System Der Politik $(1920)^{14}$. Kjellén compreende o estado como

\begin{abstract}
"forma vivente" (som livsform, em sueco, ou als Lebensform, em alemão), possuidora de instintos e pulsões naturais. Já nessa transformação da ideia de Estado, segundo a qual ele não é mais um sujeito de direito nascido de um contrato voluntário, mas um conjunto integrado por homens que se comportam como um único indivíduo ao mesmo tempo espiritual e corpóreo, pode-se encontrar o núcleo central da semântica biopolítica. $^{15}$
\end{abstract}

Ora, conhecemos intimamente as entranhas do ideal resultante de tal concepção política. O processo eugênico nazista e o ápice tecnológico de tal teleologia manifesto na câmara de gás foi muito melhor documentado do que o etnocídio ameríndio do século XVI ou a colônia belga batizada sardonicamente de Estado Livre do Congo, estabelecida entre 1877 e 1908. Tal fato, aliado à ampla popularização de sua mitologia fundamental, elevaram o Terceiro Reich a um paradigma tanatopolítico cujas bases ainda inspiram e auxiliam estudos e compreensões dos reversos infernais que a organização social humana pode engendrar ${ }^{16}$.

Será na mesma época da publicação de Cosmos que o futuro juiz Daniel Paul Schreber se encontra sob os cuidados formatadores do Geradehalter, uma invenção de seu pai, o médico Moritz Schreber. O aparelho consistia em amarrar tábuas de madeira em pontos específicos da coluna espinhal para a obtenção de uma postura exemplar. Tal artifício, combinado com os métodos totalitários de cuidados na criação do infante, levam seu filho mais velho Gustav Schreber ao suicídio, e o mais novo, Herr Senatspräsident, à confecção de um complexo delírio esquizoide para o próprio sustento do peso de sua existência. Seu famoso escrito, Memórias de um doente dos nervos (Denkwürdigkeiten eines Nervenkranken, 1903), servirá de via de acesso a Freud para a única análise sua de um caso de psicose.

$14 \mathrm{O}$ apanhado histórico da biopolítica se baseia em ESPOSITO, 2017: 22-33.

15 ESPOSITO: $2017,23$.

16 Há uma passagem de The man in the high castle, de Philip K. Dick, que ilustra habilmente o infernal matrimônio estabelecido entre política e cosmologia sob a prática nazista: "Their view; it is cosmic. Not a man here, a child there, but an abstraction: race, land. Volk. Land. Blut. Ehre. Not of honourable men but of Ehre itself, honour; the abstract is real, the actual is invisible to them. Die Güte, but not good men, this good man. It is their sense of space and time. They see through the here, the now, into the vast black deep beyond, the unchanging. And that is fatal to life. Because eventually there will be no life; there was once only the dust particles in space, the hot hydrogen gases, nothing more, and it will come again. This is an interval, ein Augenblick. The cosmic process is hurrying on, crushing life back into the granite and methane; the wheel turns for all life. It is all temporary. And these - these madmen - respond to the granite, the dust, the longing of the inanimate; they want to aid Natur" (DICK, Philip K. 45). 
Será ali que Schreber resume acreditar que "tinha a missão de redimir o mundo e restituir-lhe o estado perdido de beatitude. Isso, entretanto, só poderia realizar se primeiro se transformasse de homem em mulher"17:

\begin{abstract}
'Toda tentativa de assassinar minha alma, de emascular-me para fins contrários a Ordem das Coisas (isto é, para satisfação dos apetites sexuais de um indivíduo) ou, mais tarde, de destruir meu entendimento - toda tentativa como essa redundou em nada. Desse combate aparentemente desigual entre um débil homem e o Próprio Deus, emergi como vencedor - embora com muito amargo sofrimento e privação - porque a Ordem das Coisas está do meu lado.' (61 [cit. das Denkwürdigkeiten]) [...] A ideia de ser transformado em mulher foi a característica saliente e o germe mais primitivo de seu sistema delirante. Mostrou também ser a única parte que persistiu após a cura e a única que pôde permanecer em sua conduta na vida real, após haver-se restabelecido. 'A única coisa que poderia parecer disparatada aos olhos de outras pessoas é o fato, já aflorado no relatório do perito, de que sou às vezes encontrado parado em frente do espelho usando adornos femininos variados, tais como fitas, colares falsos e similares. Isto só ocorre, posso acrescentar, quando estou sozinho, e nunca, pelo menos na medida em que posso evitá-lo, na presença de outras pessoas.' ${ }^{38}$
\end{abstract}

Certamente o recalque da homossexualidade latente de Schreber será um ponto privilegiado na análise de Freud, que avançava no campo de descobertas das enfermidades causadas pelo abafamento da sexualidade com notável sucesso no tratamento da histeria. Entretanto, não menos importante nos é o objetivo intelectual do próprio Schreber na publicação de seu trabalho:

Onde o entendimento intelectual termina, o domínio da crença começa; o homem precisa se reconciliar com o fato de que algumas coisas verdadeiras existam mesmo que ele não possa entendê-las. Um exemplo óbvio é que o conceito de eternidade está para além da compreensão humana. $\mathrm{O}$ homem não pode realmente entender que algo possa existir sem ter começo nem fim, que pode haver uma causa impossível de ser traçada a uma causa anterior. Ainda assim a eternidade é um dos atributos de Deus, que acredito que todas as pessoas religiosas devem aceitar. O homem sempre estará inclinado a perguntar: "Se Deus criou o homem, como então Deus veio a ser?" Essa pergunta deverá permanecer eternamente sem resposta. O mesmo se aplica ao conceito da criação divina. O homem consegue sempre somente imaginar que a nova matéria é criada através da influência de forças presentes na matéria já existente, já eu acredito - e espero provar a seguir pelos meios de exemplos definitivos - que a criação divina é uma criação a partir do vazio. ${ }^{19}$

17 FREUD, 1996: 27.

18 Ibid., 30-1. Grifos do autor.

19 SCHREBER, Daniel Paul. Memoirs of my nervous illness, 2000: 16-7. 
Contra o insistente sopro de um positivismo resoluto que aperfeiçoou sua ossada desde criança de maneira a lhe fazer uma impecável prostituta de Deus, Schreber grita, em seu escrito (para ele um texto teórico, decisivo para a caminhada do pensamento em direção a um "estado de beatitude perdida"), o crucial posicionamento do espaço vazio para o ordenamento cósmico ${ }^{20}$. Torna-se manifesta a urgência de se restabelecer um regime de incompreensibilidade peremptória, de fazer com que o intelecto humano volte a se conciliar "com o fato de que algumas coisas verdadeiras existam mesmo que ele não possa entendê-las", isto é, que um caráter inexprimível da verdade deverá ser preservado, sobre o qual a frustrada transposição material acarreta um tipo de tragédia que seu próprio corpo estava fadado a testemunhar continuamente.

Tanto a biopolítica nazista quanto a Schwarze Pädagogik do Dr. Moritz Schreber partem de um princípio comum, expresso na passagem supracitada de Cosmos: a ideia de que a natureza coincide consigo mesma, ao passo em que a incongruência psicossomática é uma idiossincrasia humana a ser corrigida pela via da técnica. Dito de outro modo, o que os processos tanatopolíticos inaugurados no início do século XX - em curso nos dias de hoje, constantemente buscando diferentes vias de controle direto e indireto sobre a subjetivação nos corpos têm em comum são sua vontade de identidade, isto é, seu desejo de integrar-se plenamente ao perfeito fluxo das coisas naturais ao extirpar os bestiais parasitas (judeus, negros ou índios, gays ou deficientes) da ordem da existência cosmopolítica.

Tanto o corpo de Schreber quanto a contorção carnal das histéricas acabam por se tornar, enfim, o locus de infestação espectral do pensamento moderno europeu: ali onde a tecnológica higienização das monstruosidades procurou deixar nada além do humano, enquanto evento cósmico positivado, simétrico e equiparado a uma visão de mundo natural igualmente perfeita, as vozes de um espaço vazio de significado escancaram as portas da percepção e demandam audiências. Quando a dicotômica catequização de um mundo globalizado se vê em vias de tolher por completo as possibilidades xamânicas de devir-animal - método de diplomacia espectral por excelência -, uma pústula inflamada se abre à contragosto para o explosivo retorno do recalque espiritual de uma cultura inteira:

20 Dado ao qual Lacan certamente dará devida atenção: "Ora, se vocês considerarem o vaso, na perspectiva que inicialmente promovi, como um objeto feito para representar a existência do vazio no centro do real que se chama a Coisa, esse vazio, tal como ele se apresenta na representação, apresenta-se, efetivamente, como um nihil, como nada. E é por isso que o oleiro, assim como vocês para quem eu falo, cria o vaso em torno desse vazio com sua mão, o cria assim como o criador mítico, ex nihilo, a partir do furo" (O Seminário Livro 7: A Ética da Psicanálise, 2008: 148). 
Monstro, sim, mas que não dá mais acesso a nenhuma cosmologia. Como se houvesse na insistência dos Modernos sobre a origem interior de suas emoções algo de diabólico: essa divisão entre a mais constante de suas experiências e o que eles se autorizam a pensar disso. ${ }^{21}$

\title{
3. ABY WARBURG E A DEMONOLOGIA MODERNA
}

O meio do caminho histórico entre a primazia do significado e a exploração significante não foi gentil para com suas mais sensíveis mentes. Posicionado em um momento de virada intelectual entre o desejo de absoluto e uma genuína abertura ao infinito, o historiador da arte e "cientista da cultura" - segundo o nome da disciplina desejada pelo mesmo, a Kulturwissenschaft - Aby Warburg haverá de sucumbir sob o peso inassimilável de tal impossível conciliação. O fundador da Biblioteca para Sobrevivência da Antiguidade, mais tarde batizado Instituto Warburg; autor do Atlas Mnemosyne, no qual pretendia catalogar as maneiras através das quais as formas da arte eclodiriam em espiral ao longo de todo o tempo da memória cósmica, cai em um estado de "permanente acossamento psíquico" no ano de 1921 ao esboçar os preparativos de tal hercúlea tarefa. Escreve Fabián Ludueña:

\begin{abstract}
Para quem aspira ver a totalidade do tempo em seu devir, não há impureza temporal, e sim, pelo contrário, uma hiper-lógica que ordena as séries históricas segundo regras que obedecem a uma metafísica do infinito. Nesse sentido, a Memória a que apela o Atlas não é humana (a hybris de Warburg, sem dúvida, tinha percebido esse ponto decisivo), quando mais não seja porque evoca, num ato que nada tem de fortuito, uma Musa inumana. De algum modo, o Atlas só pode ser compreendido pelo bom Deus que vê nos detalhes e que Warburg tanto invoca. Se nos referimos a esse Deus unicamente como um hipotético ponto de observação absoluto, Mnemosyne é o nome da Memória do cosmos. A loucura de Warburg se enuncia então como um programa rigoroso: é possível conhecer essa Memória. ${ }^{22}$
\end{abstract}

Como conhecer a memória do infinito? É sabido que a viagem de Warburg aos Estados Unidos, onde famosamente testemunha o rito da serpente dos índios Hopi, acaba por estabelecer íntimas relações com seu acossamento. Sua chave de estudo, sempre marcada por distensões epistêmicas que conjugam os mais diver-

21 LATOUR, Bruno. Enquête sur les modes d'existence: une anthropologie des Modernes. 2012, apud. VALENTIM, Marco Antonio. Extramundanidade e sobrenatureza, 2018: 23. Grifos do autor original.

22 LUDUEÑA ROMANDINI, Fabián. Ascensão de Atlas, 2017: 34. 
sos saberes ${ }^{23}$, se depara com um objeto cujo espaçamento temporal lhe exige uma exploração para dentro do domínio do inumano:

Essa é, pois, uma dança de caça; nela, com o uso da máscara, o animal é apropriado como que por antecipação. [...] Tal medida não deve ser considerada algo lúdico. Afinal, para os homens primitivos, as danças mascaradas significam, dentro do processo de vinculação ao que há de mais alheio à personalidade, a mais radical das subordinações perante uma criatura demoníaca alheia. Na medida em que o índio, disfarçado em sua máscara imitadora, imita, por exemplo, um animal em sua aparência e em seus movimentos, não é por diversão que desliza para dentro dele, mas porque pretende, mediante a metamorfose de sua personalidade, sujeitar por mágica algo da natureza - tarefa que a personalidade humana não ampliada e inalterada não é capaz de realizar. ${ }^{24}$

Tarefa, dito de outra maneira, que um humano despido de sua capacidade de evadir sua pretensa autocongruência e adentrar o regime de bestialidade não seria capaz de empreender. Ainda assim, o fascínio que tal procedimento inspira nas mais íntimas profundidades da alma de um amante das artes - como sublinha Ludueña acima, a erudição de Warburg não o deixaria esquecer a qualidade titânica das musas, padroeiras cósmicas de tudo que lhe tocava - implorava por um tipo de atenção que positivista algum conseguiria dedicar. Ao flertar com o entendimento de que o sopro de inspiração das formas da arte não poderia principiar nem se encerrar dentro do alicerce antrópico, Warburg se depara com uma complexa região de temporalidade ontológica, dimensão para com a qual a modernidade buscou, a todo custo, se desvencilhar: o tempo mítico:

Esse pré-cosmos, muito longe de exibir uma 'identidade' primordial entre humanos e não-humanos, como se costuma caracterizá-lo, é percorrido por uma diferença infinita, ainda que (ou justamente porque) interna a cada personagem ou agente, ao contrário das diferenças finitas e externas que constituem as espécies e as qualidades do mundo atual. Donde o regime de multiplicidade qualitativa próprio do mito: a questão de saber se o jaguar mítico, por exemplo, é um bloco de afetos humanos em forma de jaguar ou um bloco de afetos felinos em forma de humano é indecidível, pois a 'metamorfose' mítica é um acontecimento, uma mudança não-espacial: uma superposição intensiva de es-

23 Escreve Didi-Huberman: "Warburg multiplicou as ligações entre os saberes, ou seja, entre as respostas possíveis à sobredeterminação insana das imagens - e, nessa multiplicação, é provável que tenha sonhado não escolher, adiar, não cortar nada, investir o tempo para levar tudo em consideração: loucura." ( $A$ imagem sobrevivente, 2013: 37 ).

24 WARBURG: 2015: 220-1. 
tados heterogêneos, antes que uma transposição extensiva de estados homogêneos. ${ }^{25}$

O imperativo de concepção da alteridade efervescente que constitui os personagens no plano mítico da experiência xamânica, expresso na capacidade de "trocar de pele" através do rito metamórfico, acaba por figurar como elemento decisivo para a construção da disciplina almejada por Warburg. Afinal, aquilo que a "lei da boa vizinhança" de organização de sua Biblioteca deixa transparecer é que "até cada intervalo entre os livros" se encontra assombrado, como um "corpo espectral [...] sem contornos definíveis" ${ }^{26}$ : seu desejo holístico, pautado antes de mais nada por sobre uma necessidade abissal de honrar a complexidade de seus objetos - "[u]ma 'sopa de enguias' teórica, em suma"27 - levava água necessariamente aos espaços de transição, intermediários, de infecciosos não-mais e não-ainda, ao invés de buscar deter maior compromisso libidinal para com o encerramento absoluto de disciplinas bem consolidadas.

Ora, o intermediário (metaxú) é o espaço por excelência do daímon na cosmologia platônica. Platão assim desenha, em $O$ Banquete, o espaço de exercício do poder daimônico:

$\mathrm{O}$ [poder] de interpretar e transmitir aos deuses as mensagens dos homens e aos homens as dos deuses: de uns, as preces e sacrifícios; dos outros, os comandos e as compensações pelos sacrifícios recebidos. Por se encontrar em um lugar intermediário entre ambos, completa-os, de modo que todo fique coligado consigo mesmo (hoste tò pân autò autô sundedésthai). Através dele, discorre toda a mântica e a arte sagrada (tôn hierôn téchne) relativa a sacrifícios, iniciações, conjurações, adivinhações e encantamentos. O deus não se mescla com o homem, mas, através desse daímon, dá-se toda tratativa e conversa dos deuses para com os homens, tanto em vigília como durante o sono [...] Esses daímones são muitos e variados: e um deles certamente é Eros. ${ }^{28}$

O poder de estabelecer laço comunicativo entre seres sublunares e celestiais, ou, numa extrapolação ameríndia, entre humanos e não-humanos, através do intrincado circuito passional de imagens e imaginações conjurado em Mnemosyne, parece dizer do terreno que assombrava Warburg em seu fazer. Essa "diferença infinita interna”, princípio ontológico radicalmente distinto do ideal identitário 
praticado pela biopolítica nazista em gestação durante os anos decisivos de sua pesquisa, pode muito bem ter sido uma das razões de seu acossamento.

Como nos escritos do presidente Schreber, seguimos percebendo o peso que o imperativo de congruência identitária próprio do positivismo moderno pode conceber ao expurgar todo espaço de fora-do-sentido, de onde falam as vozes espectrais que atuam sob e sobre os corpos. A disciplina artística de Warburg, essa forma de demonologia moderna ${ }^{29}$, segue sendo o epicentro de estudiosos das incongruências e dos saberes em trânsito, das maneiras poéticas segundo as quais a psique humana parece constantemente fazer experiência de seus decisivos deslizes para fora do cogito. Sua biblioteca - "biblioteca de trabalho, [...] mas também biblioteca em trabalho" 30 -, situada em Londres desde a fuga do regime nazista, se fez um ponto de sobrevivência das fantasmagorias arcaicas, um local onde os acadêmicos acossados podem invocar a transitoriedade daimônica na infindável pesquisa das conjugações possíveis entre as formas dos saberes do velho e do novo. Uma complexa diplomacia, cuja operação temporal o próprio Warburg brilhantemente resume em sua Introdução à Mnemosine [sic]: "[...] a ciência, ao fazer seus registros, grava e transmite a estrutura rítmica na qual os monstros da fantasia se tornam os condutores da vida e determinam o futuro" ${ }^{\text {"11. }}$.

\section{INCONGRUÊNCIA IDENTITÁRIA}

Iniciamos o artigo com a proposição de um contraponto ao ideal cosmológico do determinismo fechado que, ao que tudo indica, opera como berço da organização lógica própria da biopolítica. A subsequente exposição de dois casos paradigmaticamente sintomáticos ${ }^{32}$ de uma época marcada pelo profundo desejo de auto-identificação dos corpos nos permitiu o vislumbre de situações nas quais demandas somáticas advindas de uma zona situada para além do sentido se fazem manifestas, frustrando os ideais teleo-tautológicos de uma era.

Definitivamente, o desejo de auto-encerramento do poder sobre si mesmo não esvaeceu à virada do século XX para o XXI. Imperativos amplamente comercializados sob a falaciosa etiqueta be yourself podem, antes de mais nada,

\footnotetext{
29 "Na realidade, a 'ciência sem nome' que Warburg praticava e de cuja conceitualização tentava se aproximar, muitas vezes com o rústico vocabulário da biologia de seu tempo, tinha já um passado milenar. Logo, tinha também um nome, que a 'superstição' delirante de Warburg (e seus consequentes escrúpulos acadêmicos) não o deixava pronunciar, mas que ele conhecia perfeitamente. Não se tratava de uma iconologia, muito menos de uma antropologia; Warburg desejou assentar as bases de uma demonologia à altura da era tecnológica" (LUDUEÑA ROMANDINI: 2017, 31).

30 DIDI-HUBERMAN: 2013, 35.

31 WARBURG: 2015, 365.

32 "[...] o caso Warburg testemunha um íntimo copertencimento entre ciência e loucura. Nesse sentido, a obra de Warburg, toda ela, é seu sintoma” (LUDUEÑA ROMANDINI: 2017, 29).
} 
comprovar a rápida disposição da forma capitalista de fagocitar investidas de sabotagem, como o fez com os ideais libertários de 68. De mesmo modo, a epidemia de diagnósticos de bipolaridade, ponto de erupção da paradoxal disposição subjetiva para materializar todas as metas ao mesmo tempo em que reconhece a si própria como descartável, é apenas uma das incontáveis manifestações de insuficiência dos modos de distribuição onírica no Antropoceno:

\begin{abstract}
Nesse sentido, o homem contemporâneo poderia se considerar despossuído de seu comércio com aquelas potências uma vez chamadas dáimones. Contudo, seu drama parecer estar antes na incapacidade de propiciá-las novamente e acolhê-las em suas imagens, pois carece da hexis corporal e das coordenadas de uma cartografia que, embora continue presente, tornou-se historicamente ilegível. ${ }^{33}$
\end{abstract}

Seria um exagero grosseiro extrapolar a infernal teleologia nazista em sua manifestação biopolítica como um mal subjacente a todas as lutas identitárias, hoje em dia imensamente numerosas, uma vez que a principal consequência no âmbito sociocultural de tais focos de movimentação política é a redução de absolutos à categorias. Somente através desse processo de pensamento é que se torna possível entender as catastróficas condições que todos os horizontes científico-políticos apontam para o mundo capitalista globalizado como resultado de programas pontuais e específicos, e não como ações pré-determinadas de uma "natureza humana" absolutizada ${ }^{34}$.

Entretanto, o preço por ignorar a rachadura ontológica de onde falam as vozes espectrais, que roubam Homo de sua serenidade autocentrada, é igualmente catastrófico. Assim, torna-se necessário apontar uma próxima volta do parafuso e relembrar que o espaço democrático é justamente um locus político dado às contingências do incalculável ${ }^{35}$, segundo as quais aglomerado algum pode alme-

33 LUDUEÑA ROMANDINI: 2017, 71-2.

34 "Diferentemente, pensar a sobrenatureza da catástrofe implica concebê-la como resultado de uma 'guerra [ontológica] de mundos' [...], na qual humanos e não-humanos, vivos e não-vivos, espíritos e máquinas, indígenas e alienígenas, se imaginam e contraimaginam uns aos outros, segundo metafísicas heterogêneas e incomensuráveis, como que em mútua projeção espectral" (VALENTIM: 2018, 24).

35 Aos seis chamados "títulos naturais de governo", que eram o poder dos pais sobre os filhos; dos velhos sobre os jovens; dos mestres sobre os escravos; das pessoas bem-nascidas sobre os sem-nada; dos mais fortes sobre os menos fortes; dos sábios sobre os ignorantes; somava-se, na pólis grega, por fim o sétimo que caracterizava em definitivo a democracia: o sorteio, o título do "amado pelos deuses", cuja única autoridade era a completa ausência de autoridade de um lance de dados: "Ora, o 'sétimo título' mostra que não há necessidade de sacrifícios ou sacrilégios para romper com o poder da filiação. Basta um lance de dados. O escândalo é simplesmente o seguinte: entre os títulos para governar, existe um que quebra a corrente, um que refuta a si mesmo. O sétimo título é a ausência de título. Essa é a confusão mais profunda expressa pela palavra democracia. Não se trata de fera rugindo, asno orgulhoso ou indivíduo guiado por seus caprichos. Está claro 
jar encerrar sua construção dentro da virtualidade do ideal.

O efeito sedativo da asserção de si tem necessariamente pernas curtas: apontar tal limitação de maneira alguma implica desdenhar das imprescindíveis consequências imediatas que os acertos históricos atualmente em construção têm a oferecer. O terreno dos termos explorados no presente escrito - espectro, daímon, sobrevivência, sintoma - busca, por sua vez, fazer circular léxicos que possibilitem uma visão não simplificada das relações humanas com o sentido e, principalmente, o fora-de-sentido, no âmbito de suas integrações coletivas.

Tal é a tarefa política dentro dos termos de nossa cosmologia diastásica.

\section{REFERÊNCIAS}

DARDOT, Pierre; LAVAL, Christian. A nova razão do mundo: Ensaio sobre a sociedade neoliberal. Trad. Mariana Echalar, São Paulo: Boitempo Editorial, 2016.

DIDI-HUBERMAN, Georges. A imagem sobrevivente: História da arte e tempo dos fantasmas segundo Aby Warburg. Trad. Vera Ribeiro, Rio de Janeiro: Contraponto Editora, 2013.

ESPOSITO, Roberto. Bios: Biopolítica e filosofia. Trad. Wander Melo Miranda, Belo Horizonte: Editora UFMG, 2017.

FREUD, Sigmund. O caso Schreber, Artigos sobre Técnica e outros trabalhos (1911 1913), Trad. José Octávio de Aguiar Abreu e Christiano Monteiro Oiticica, Rio de Janeiro: Imago Editora, 1996.

KANT, Immanuel. Ideia de uma historia universal de um ponto de vista cosmopolita. Trad. Rodrigo Naves e Ricardo R. Terra São Paulo: Brasiliense, 1986.

LUDUEÑA ROMANDINI, Fabián. Ascensão de atlas: Glosas sobre Aby Warburg. Trad. Felipe Augusto Vicari de Carli, Florianópolis: Cultura e Barbárie Editora, 2017.

Princípios de espectrologia: A comunidade dos espectros II. Trad. Leonardo d’Ávila e Marco Antonio Valentim, Florianópolis: 2018.

que essas imagens são maneiras de esconder o fundo do problema. A democracia não é o capricho das crianças, dos escravos ou dos animais. É o bel-prazer do deus, o deus do acaso, de uma natureza que arruína a si mesma, como princípio de legitimidade. A desmedida democrática não tem nada a ver com uma loucura consumista qualquer. É simplesmente a perda da medida com a qual a natureza regia o artifício comunitário através das relações de autoridade que estruturam o corpo social. O escândalo é o de um título para governar completamente distinto de qualquer analogia com aqueles que ordenam as relações sociais, de qualquer analogia entre a convenção humana e a ordem da natureza. É o de uma superioridade que não se fundamenta em nenhum outro princípio além da própria ausência de superioridade" (RANCIÊRE: 2014, 56). 
NIETZSCHE, Friedrich Wilhelm. A gaia ciência. Trad. Paulo César de Souza, São Paulo: Companhia das Letras, 2012.

RANCIÈRE, Jacques. O ódio à democracia. São Paulo: Boitempo Editorial, 2014.

SCHREBER, Daniel Paul. Memoirs of my nervous illness, Trad. Ida Macalpine, New York: New York Review Books, 2000.

VALENTIM, Marco Antonio. Extramundanidade e sobrenatureza: Ensaios de ontologia infundamental. Florianópolis: Cultura e Barbárie Editora, 2018.

WARBURG, Aby. Histórias de fantasma para gente grande: escritos, esboços e conferências. Org.: Leopoldo Waizbort, Trad.: Lenin Bicudo Bárbara, São Paulo: Companhia das Letras, 2010.

\title{
IDENTITARIAN INCONGRUITY AND SPECTRAL DIPLOMACY
}

\begin{abstract}
Can the subject coincide with itself? A negative approach to such question is the touchstone of psychoanalysis, clinical answer to a movement of western thought prepared in mid twentieth century, which will find its concreteness in effervescence by the beginning of the next. A great change in spirit, characterized by the exhaustion of obsessive philosophical work around the idea of an absolute, perfect and infinite, opens space for a scientific exploration of the landscapes where the cogito fails: in psychoanalysis, Freud, the unconscious and the cases of hysteria; on Cultural Studies, Warburg, the Atlas Mnemosyne and his schizophrenia. Affections organized in regions beyond the domains of sense, of spectral nature, symptomatically return demanding attention, in the moments in which a desire for psychosomatic auto-congruity seeks to perform technical materializations naturally insurmountable.
\end{abstract}

Keywords: Spectrology. Symptom. Incongruity. Daímon. 